PRODUÇÃO ARTESANAL DO QUEIJO DE LEITE CRU: DILEMAS DO DESENVOLVIMENTO AGRÍCOLA BRASILEIRO

Tese de Doutorado

Orientador: Prof. Titular Gilberto Bercovici

UNIVERSIDADE DE SÃO PAULO

FACULDADE DE DIREITO

São Paulo - SP

2018 



\section{PRODUÇÃO ARTESANAL DO QUEIJO DE LEITE CRU: DILEMAS DO DESENVOLVIMENTO AGRÍCOLA BRASILEIRO}

Tese apresentada à Banca Examinadora do Programa de Pós-Graduação em Direito, da Faculdade de Direito da Universidade de São Paulo, como exigência parcial para obtenção do título de Doutor em Direito, na área de Concentração Direito Econômico e Financeiro, sob a orientação do Prof. Titular Gilberto Bercovici.

UNIVERSIDADE DE SÃO PAULO

FACULDADE DE DIREITO

São Paulo - SP

2018 
Catalogação da Publicação

Serviço de Biblioteca e Documentação

Faculdade de Direito da Universidade de São Paulo

Braga, Marco Aurelio Cezarino

Produção Artesanal do Queijo de Leite Cru: dilemas do desenvolvimento agrícola brasileiro / Marco Aurelio Cezarino Braga ; orientador Gilberto Bercovici -- São Paulo, 2018.

$230 \mathrm{p}$.

Tese (Doutorado - Programa de Pós-Graduação em Direito. Direito Econômico, Financeiro e Tributário) - Faculdade de Direito, Universidade de São Paulo, 2018.

1. Produção artesanal de queijo de leite cru. 2. Direito Econômico - Brasil. 3. Regulação Sanitária. 4. Regulação de Produtos de Origem Animal. 5. Desenvolvimento regional. I. Bercovici, Gilberto, orient. II. Título. 
Nome: BRAGA, Marco Aurélio Cezarino

Título: Produção artesanal e agroindústria: dilemas do desenvolvimento agrícola brasileiro

Tese apresentada à Banca Examinadora do Programa de Pós-Graduação em Direito, da Faculdade de Direito da Universidade de São Paulo, como exigência parcial para obtenção do título de Doutor em Direito, na área de Concentração Direito Econômico e Financeiro, sob a orientação do Prof. Titular Gilberto Bercovici.

Aprovado em:

\section{Banca Examinadora}

Prof. Dr.

Instituição:

Julgamento:

Prof. Dr.

Instituição:

Julgamento:

Prof. Dr.

Instituição:

Julgamento:

Prof. Dr.

Instituição:

Julgamento:

Prof. Dr.

Instituição:

Julgamento: 

Dedico este estudo aos produtores da Serra da Canastra e à gente simples e honrada que vive da terra em nosso país. 



\section{AGRADECIMENTOS}

Este trabalho é muito mais fruto das pessoas com quem convivi do que da solidão em que construí alguns poucos pensamentos e reflexões. É a eles a quem devo agradecer.

Agradeço ao meu orientador, Professor Gilberto Bercovici, a quem devo a honra da convivência (e da paciência) dos últimos dez anos. Professor, o senhor soube me confortar nos momentos mais difíceis desta caminhada, sempre com bom humor, sugestões e conselhos precisos. Sou muito grato, também, por ter tido a oportunidade de acompanhar e aprender em seus cursos de Direito Econômico, de Economia Política e ter contado com seu apoio nos primeiros passos da docência.

Agradeço ao amigo Leandro Pereira, quem primeiro me descortinou a aventura do queijo Canastra e sua gente. Um convite singelo que mudou definitivamente os rumos de minha vida.

Agradeço aos produtores da Serra da Canastra com quem tive a honra de muito, muito, aprender. Ao Joãozinho, nosso mestre, pelas horas infindáveis de conversas e ensinamentos sobre o queijo e a vida, Ao Guilherme, parceiro e irmão. Ao Paulo, pelo apoio constante e alegre. Ao Ricardo Boscaro, pelo cuidado e dedicação que tem com os produtores e suas histórias. Agradeço à convivência com o Seu Zé Mario, Ivair, Lúcia, Valéria, Claudiano e Andressa (e o pequeno João Carlos), Solange, Júlia e a todos os outros produtores.

Agradeço ao professor Luis Fernando Massonetto pelas valorosas sugestões bibliográficas e todo diálogo ao longo da pesquisa, tanto em minha qualificação quanto nas conversas que se seguiram. Seu incentivo e reflexões auxiliaram muito na caminhada.

Agradeço ao professor José Tadeu de Chiara pela arguição e ensinamentos ao longo das disciplinas da pós-graduação.

Agradeço ao Eduardo Saad Diniz, Fabrício Nascimento, Bruna Angotti, Marco Ruiz, Rubens Silveira e José Guilherme Moreno Caiado, pela leitura e revisões 
atentas, além das sugestões que confortaram as angústias ao longo da redação. Sou muito grato pelo tempo, ensinamentos e atenção de vocês. Agradeço também à Giovana Romano Sanchez pela transcrição das entrevistas que realizaei.

Este trabalho não seria possível sem que eu tivesse o apoio, a confiança e a compreensão inigualáveis de meu sócio e amigo, Luiz Carvalho, e de minha equipe talentosa e dedicada: Gabi, Fabrício, Henrique e Tagie; Beth, Camila, Neide e Tânia, além dos demais colegas de escritório, espero poder retribuir minha ausência com a gratidão que sempre carregarei por tê-los por perto.

Agradeço a Universidade Pública, por ter proporcionado os recursos e espaços para que essa pesquisa pudesse se desenvolver.

Agradeço à minha família, que soube suportar e respeitar minha ausência e recolhimento. Muito obrigado!

Agradeço à Regina, a quem devo tudo e que me inspira a continuar sonhando e lutando. 
"Marco, pega um queijo novinho meu e uma nota de dez reais Coloca os dois numa prateleira de madeira Todo dia, cê passa lá e vira. O queijo e a nota Faz isso todo dia: limpa o queijo... limpa a nota cuida do queijo... cuida da nota Dali trinta dias, o meu queijo que valia dez vai tá valendo cinquenta E a sua nota, vai tá valendo quanto?" Ivair, produtor artesanal de queijo Canastra 



\section{RESUMO (PORTUGUÊS)}

Este trabalho pretende situar, pelo método próprio ao Direito Econômico, o debate sobre a produção artesanal de queijo de leite cru, que vive atualmente uma situação sui generis do ponto de vista legal e econômico. Partimos do diagnóstico de que a legislação nacional que regula a produção de alimentos de origem animal privilegia a adoção de métodos industriais e controles sanitários para distintas realidades produtivas - tanto em escala, métodos de produção, valores culturais, prática de preços e mercados de consumo. Esta problemática será analisada tanto em função de seus elementos econômicos, como também preocupada com a proteção jurídica de outros bens adjacentes (ou contraditórios) ao processo de acumulação capitalista, tais como a preservação do patrimônio históricocultural brasileiro e a superação das desigualdades regionais. Neste sentido, o trabalho traça o histórico no qual se insere a produção agroartesanal brasileira desde o século XVI até o início do século XXI. Essa reconstrução nos permitirá situar a regulação dos produtos de origem animal, principalmente a partir da edição da Lei 1.283/1950 e do Decreto 30.691/1952 (que cria o RIISPOA), que contêm regras de controle industrial e sanitário para a produção de alimentos, as quais afastaram práticas até então comuns da produção de queijo de leite cru no país. Essa reconstrução buscará analisar as perspectivas histórica, social, econômica e cultural em que se situa o texto jurídico, extraindo daí a economia política na qual se insere a regra jurídica. Por fim, a partir do método do estudo de caso, analisamos os efeitos desta regulação sobre a Região da Serra da Canastra, para em seguida propor sugestões legais que consideram e respeitam a produção artesanal de queijo local, harmonizando a legislação e promovendo sua maior sintonia com o pacto federativo cooperativista inserido na Constituição de 1988 e nos princípios de nossa

política agrícola, reconhecendo e valorizando econômica e culturalmente a produção artesanal de queijo de leite cru.

Palavras-chave: queijo artesanal, queijo de leite cru, regulação de produtos de origem animal, direito econômico, política agrícola, produção agroartesanal. 



\begin{abstract}
The purpose of this study is to apply the Economic Law method for analyzing the artisanal raw-milk cheese production, which currently experiences a sui generis treatment from a legal and economic perspective in Brazil. Our initial diagnosis reveals a staggering slant of the Brazilian legal framework for food product of animal origin toward the fostering of similar industrial methods and sanitary controls for the most different production circumstances, regardless of production scale, cultural values, pricing and consumer markets. The research assesses the issue's economic basis, as well as the legal protection of values close (or even contradictory) to the capitalist accumulation, such as the preservation of cultural heritages and the regional inequality overcome. In this sense, the work provides a historical background for the Brazilian agroartisanal production from the 16 th century through the early 21 th century. Such background permits a historical understanding of the animal origin products' regulation, especially after the enactment of Law no. 1,283/1950 and Decree no. 30,691/1952, which establishes the "RIISPOA" and provide rules of industrial and sanitary control for food production, endangering the untilthen common practices of raw-milk cheese production in Brazil. The objective of the historical review is to enable an analysis on the social, economic and cultural basis of the legal wording, to understand the political economy in which the legal rule is embedded. In conclusion, by means of a case study method, we examine the effects of the current legal framework upon the Serra da Canastra region. As a result, the research provides legal suggestions for harmonizing the legal framework with the local cheese production, the federal cooperative pact inserted in the Federal Constitution from 1988 and the principles of the Brazilian agricultural policies, recognizing and promoting the raw-milk artisanal cheese production both economically and culturally.
\end{abstract}

Keywords: raw-milk cheese, artisanal cheese, legal framework for food product of animal origin, economic law, agricultural policy, artisanal production. 



\section{RÉSUMÉ}

Le but de cette étude est d'appliquer la méthode du droit économique sur l'analyse de la production artisanale du fromage au lait cru, lequel fait actuellement l'objet d'un traitement sui generis d'un point de vue juridique et économique au Brésil. Notre diagnostic initial révèle une orientation stupéfiante du cadre juridique brésilien pour les produits alimentaires d'origine animale vers la promotion de méthodes industrielles et de contrôles sanitaires similaires pour les conditions de production les plus différentes, indépendamment de l'échelle de production, des valeurs culturelles, des prix et des marchés consommateurs. La recherche évalue la base économique du problème, ainsi que la protection juridique des valeurs proches (voire contradictoires) de l'accumulation capitaliste, telles que la préservation des héritages culturels et l'inégalité régionale vaincue. En ce sens, le travail fournit un arrière-plan historique pour la production agroartisanale brésilienne du 16ème siècle au début du 21ème siècle. Un tel contexte permet une compréhension historique de la réglementation des produits d'origine animale, en particulier après la promulgation de la loi no. 1 283/1950 et le décret no. 30,691/1952, qui établissent le "RIISPOA" et fournissent des règles de contrôle industriel et sanitaire pour la production alimentaire, mettant en danger les pratiques jusqu'alors communes de la production de fromage au lait cru au Brésil. L'objectif de la reprise historique est de permettre une analyse sur la base sociale, économique et culturelle de la formulation juridique afin de comprendre l'économie politique dans laquelle la règle juridique est ancrée. Finalement, à travers une méthode d'étude de cas, nous examinons les effets du cadre juridique actuel sur la région de la Serra da Canastra. Par conséquent, la recherche fournit des suggestions juridiques afin d'harmoniser le cadre juridique et la production locale de fromage, le pacte de coopération fédéral inséré dans la Constitution de 1988 et les principes des politiques agricoles brésiliennes, tout en reconnaissant et promouvant la production de fromage artisanal au lait cru, à la fois économiquement et culturellement.

Mots-clés : fromage au lait cru, fromage artisanale, cadre juridique pour les produits alimentaires d'origine animale, politique agricole, production agroartisanale. 



\section{LISTA DE SIGLAS}

\begin{tabular}{|c|c|}
\hline ABIA & Associação Brasileira da Indústria da Alimentação \\
\hline APQA & Associação Paulista de Queijos Artesanais \\
\hline APROCAME & Associação dos Produtores de Queijo da Canastra de Medeiros \\
\hline APROCAN & Associação dos Produtores de Queijo da Canastra \\
\hline BDTD & Biblioteca Digital de Teses e Dissertações \\
\hline $\mathrm{BPF}$ & $\begin{array}{l}\text { Boas Práticas de Fabricação } \\
\text { Código Internacional Recomendado de Práticas Gerais de Higiene dos }\end{array}$ \\
\hline CAC & Alimentos \\
\hline CAI & Complexo Agroindustrial \\
\hline CBT & Contagem Bacteriana Total \\
\hline Cepal & Comissão Econômica para a América Latina e o Caribe \\
\hline CONSEA & Conselho Nacional de Segurança Alimentar \\
\hline DIPOA & Departamento de Inspeção de Produtos de Origem Animal \\
\hline DNPA & Departamento Nacional de Produção Animal \\
\hline EPAMIG & Empresa de Pesquisa Agropecuária de Minas Gerais \\
\hline FAEMG & Federação da Agricultura e Pecuária do Estado de Minas Gerais \\
\hline FAO & Organização das Nações Unidas para a Alimentação e a Agricultura \\
\hline FAPESP & Fundação de Amparo à Pesquisa do Estado de São Paulo \\
\hline GMC & Grupo Mercado Comum \\
\hline IBGE & Instituto Brasileiro de Geografia e Estatística \\
\hline IBICT & Instituto Brasileiro de Informação em Ciência e Tecnologia \\
\hline IMA & Instituto Mineiro de Agropecuária \\
\hline IN & Instrução Normativa \\
\hline INPI & Instituto Nacional de Propriedade Industrial \\
\hline IPHAN & Instituto do Patrimônio Histórico e Artístico Nacional \\
\hline MAPA & Ministério da Agricultura, Pecuária e Abastecimento \\
\hline MDA & Ministério do Desenvolvimento Agrário \\
\hline Mercosul & Mercado Comum do Sul \\
\hline $\mathrm{OMC}$ & Organização Mundial do Comércio \\
\hline PIB & Produto Interno Bruto \\
\hline PM & Polícia Militar \\
\hline PMDF & Polícia Militar do Distrito Federal \\
\hline QMA & Queijo Minas Artesanal \\
\hline RIISPOA & Regulamento de Inspeção Industrial e Sanitária de Produtos de \\
\hline RITQ & Regulamento Técnico de Identidade e Oualidade \\
\hline & Regulamentos Técnicos de Identidades e Qualidades de Produtos \\
\hline RTIQ & Lácteos \\
\hline SABRAE & Serviço Brasileiro de Apoio às Micro e Pequenas Empresas \\
\hline SAROMCREDI & Cooperativa de Crédito de São Roque de Minas \\
\hline SDA & Secretaria da Defesa Agropecuária \\
\hline
\end{tabular}


SICOOB- $\quad$ Sistema de Cooperativas de Crédito do Brasil - NÃO ENCONTREI O

Saromcredi OUTRO

SIF Serviço de Inspeção Federal

SISBI-POA Sistema Brasileiro de Inspeção de Produtos de Origem Animal

SISBI-POV Sistema Brasileiro de Inspeção de Produtos de Origem Vegetal

SUASA Sistema Unificado de Atenção a Sanidade Agropecuária

SUS Sistema Único de Saúde

UHT Ultrapasteurização

USP Universidade de São Paulo 


\section{SUMÁRIO}

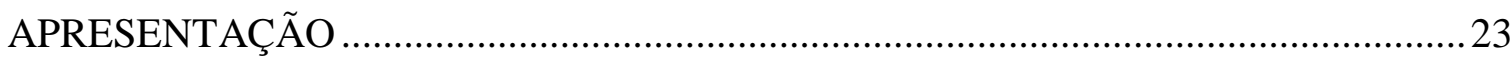

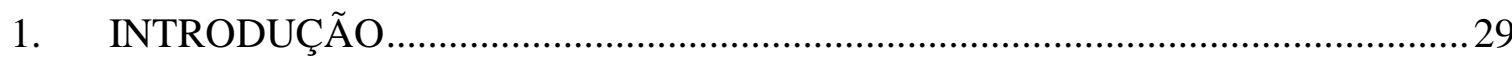

2. ECONOMIA POLÍTICA DA PRODUÇÃO de queijos NO BRASIL ......................45

2.1 BREVE HISTÓRIA DA PRODUÇÃO QUEIJEIRA NO MUNDO ................48

2.2.1. A descoberta da pasteurização em 1864 ......................................................57

2.2.2. A melhoria industrial dos insumos para a produção de queijo e a revolução

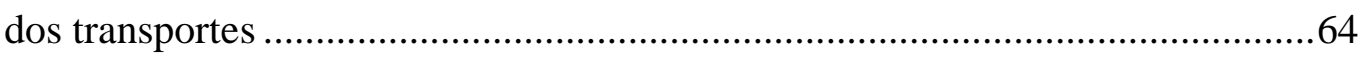

2.2 HISTÓRIA DA PRODUÇÃO QUEIJEIRA NO BRASIL ................................69

2.2.1. Economia colonial e a produção de queijos no Brasil ..................................69

2.2.2. Império e o fomento da Coroa ao desenvolvimento das técnicas agrícolas ..

2.2.3. Conclusões parciais sobre a especificidade do modelo brasileiro de

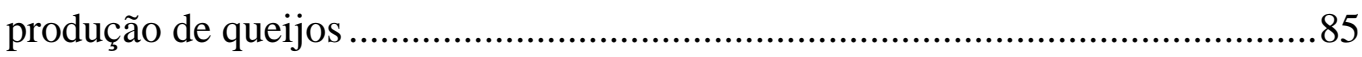

2.2.4. Economia queijeira e a ordem escravocrata …………………………......90

2.2.5. Fundação da República e o início do processo de industrialização da

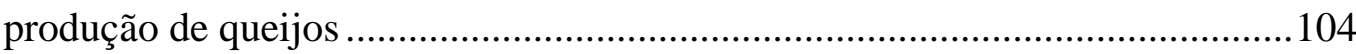

3. POLÍTICA AGRÍCOLA E PRODUÇÃO DE QUEIJOS NO BRASIL A PARTIR

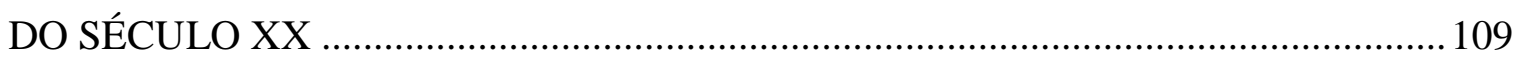

3.1 QUESTÕES PRELIMINARES: SANITARISMO E ABASTECIMENTO NA

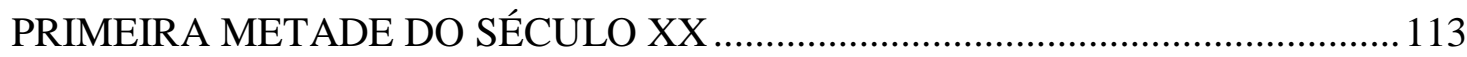

3.1.1. Sanitarismo e saúde pública: ideia-força para o controle industrial e sanitário dos produtos de origem animal 114

3.1.2. Políticas de abastecimento e o problema da carestia: ideia-força para o controle industrial e sanitário dos produtos de origem animal

3.1.3. A forma jurídica da organização do Estado para a estruturação produtiva ...

3.2 QUESTÃO AGRÁRIA, INDUSTRIALIZAÇÃO E BREVE CONTEXTUALIZAÇÃO DA ESTRUTURA PRODUTIVA DO BRASIL NO

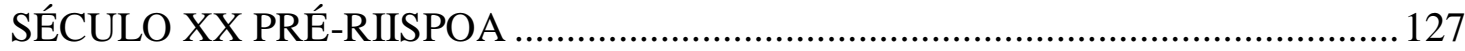

3.2.1. A direção do processo de estruturação produtiva no Brasil ......................128

3.3 REGULAÇÃO DA PRODUÇÃO DE QUEIJOS NO BRASIL A PARTIR

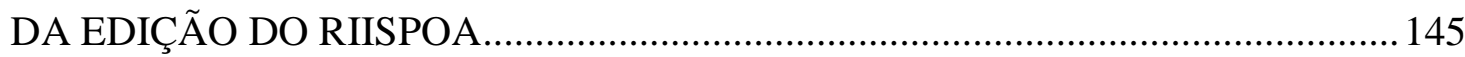


3.2.1. O Regulamento da inspeção industrial e sanitária de produtos de origem animal contido no Decreto 30.691/1952 .........................................................149

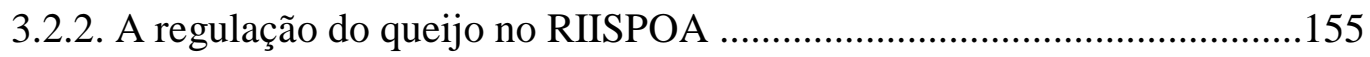

3.2.3. Inspeção industrial e sanitária a partir da Constituição de 1988: federalismo e política agrícola nas adequações ao RIISPOA ............................172

3.2.4 Leis 7.889/1989 e 8.171/1991: incorporação do modelo constitucional à divisão de competências da regulação de alimentos de origem animal.............177

3.2.5. Nova revisão do RIISPOA pelo Decreto 9.013/2017: reorganização, não reorientação

3.2.6. A influência do sanitarismo, food safety e food security na regulação do queijo de leite cru no Brasil

3.2.7. Contornos e transtornos da produção e comercialização de queijos artesanais de leite cru: da produção 'ilegal' ao reconhecimento cultural e regional

4. ESTUDO DE CASO: ALTERNATIVAS PARA A REGULAÇÃO DA PRODUÇÃO AGROARTESANAL DE QUEIJO DE LEITE CRU A PARTIR DA EXPERIÊNCIA DOS PRODUTORES DA SERRA DA CANASTRA ….......................213

4.1 CARACTERIZAÇÃO DA REGIÃO DA SERRA DA CANASTRA E SEU MODO ARTESANAL DE PRODUZIR QUEIJOS .............................................218

4.1.1. Conclusões do diagnóstico da região ...................................................228

4.2 UMA READEQUAÇÃO DOS MEIOS AOS (NOVOS) FINS DA POLÍTICA AGRÍCOLA: O CONTROLE SANITÁRIO DO MODO ARTESANAL DE

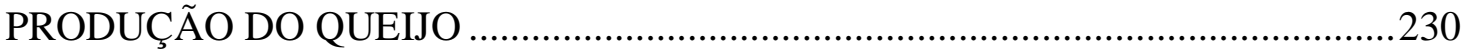

4.3 AGENDA LEGISLATIVA E REGULAÇÃO SANITÁRIA DA PRODUÇÃO

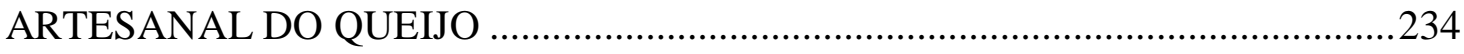

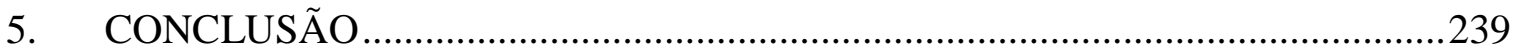

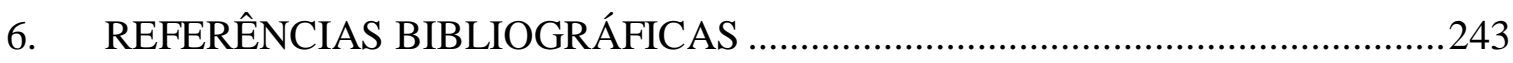




\section{APRESENTAÇÃO}

Inicialmente, minha pesquisa de doutorado tinha outra estrutura e propósito, pois me propunha a pesquisar instrumentos legais adequados à promoção da Indústria da Defesa no Brasil e as discussões em torno do poder de compra do Estado como indutor do desenvolvimento tecnológico. Todavia, foi em uma visita a São Roque de Minas/MG que mudou os rumos desta pesquisa. Mais especificamente, entre os dias 20 a 22 de novembro de 2015, numa cidade integrante da Serra da Canastra e reconhecida por sua produção artesanal de queijo de leite cru há mais de dois séculos. Com o objetivo de observar tal produção, optei por alterar drasticamente os rumos da pesquisa e dedicar-me à essa questão.

Convidado por um amigo a conhecer a Serra da Canastra e seus produtores rurais de queijo de leite cru, não imaginava que isso me conduziria por caminhos tão inusitados, a ponto de mudar o eixo de minha pesquisa de doutoramento, debruçando-me, assim, nas discussões sobre os meios de se produzir, de comercializar e de viver do queijo, ainda não reconhecidos adequadamente pelo Estado brasileiro em suas três esferas federativas - tornando-se, desse modo, uma das minhas justificativas acerca da mudança no tema.

Durante aquele final de semana, as visitas às fazendas eram sempre regadas de produtos da região: seu café, seus queijos, seus doces de compota. No entanto, as prosas que acompanhavam as mesas fartas giravam em torno da "ilegalidade", da "falta de reconhecimento" da "lei anacrônica" que interferia pesadamente na realidade daqueles produtores e seus produtos. Histórias que conviviam com uma cidade que, até pouco tempo atrás, "morria devagar" (CARVALHO; LEITE, 2004, p. 44).

A dualidade do cenário - de aparente abundância e velada ilegalidade dialogava com aspectos estudados durante as disciplinas da pós-graduação. Nas aulas dos professores Bercovici e Massonetto em torno das dimensões do Estado Intervencionista, chamava minha atenção a discussão em torno das formas como o direito lida com a intertemporalidade e com o espaço. Embora retomaremos a tal discussão nos próximos capítulos, ressalto um possível devaneio traçado por suas trilhas: colocar os produtores da 
Canastra para dialogar com Arrighi, Braudel e Furtado não seria muita loucura, pois uma série de aspectos daquela realidade vivida se encontravam com a realidade estudada. Logo, estava clara para mim a oportunidade de relacionar os debates em torno da intervenção do Estado na regulação daquela atividade econômica, relacionando seus efeitos na realidade daquele campo e seus produtores.

Assim, estava clara para mim a oportunidade de relacionar os debates em torno da intervenção do Estado na regulação daquela atividade econômica, relacionando seus efeitos na realidade daquele campo e seus produtores.

Na manhã de domingo, 22 de novembro, visitamos a fazenda Roça da Cidade para ouvir a história de João Carlos Leite, conhecido como Joãozinho, produtor reconhecido nacionalmente por seu trabalho em defesa de São Roque de Minas e do cooperativismo de crédito. Foi um dos fundadores do banco cooperativo da cidade na década de 1990, o SICOOB-Saromcredi, responsável por uma verdadeira revolução no acesso ao crédito e pelo consequente renascimento da cidade - que experimentou um dos maiores crescimentos do PIB em todo Brasil durante o período. Seu histórico de luta em defesa da cidade e de sua economia se iniciou após o fechamento do posto avançado do banco Bradesco, que retirou o dinheiro de circulação da cidade, agravou a escassez de crédito e fez com que, em cerca de 10 anos, a cidade tipicamente agrícola tivesse sua população reduzida de 12.000 para cerca de 6.000 (CARVALHO; LEITE, 2004, p. 107120).

Naquele encontro, depois de degustarmos os queijos de leite cru produzidos na fazenda há três gerações, tivemos uma aula sobre a relação do queijo com a história das civilizações: de maneira simples e à moda mineira, o produtor rural nos narrou a descoberta casual do talho do leite quando em contato com o estômago dos animais, cerca de 2.000 anos antes de Cristo; explorou a relação do queijo com a alimentação das tropas romanas; a sua importância nas navegações para a conquista das Américas; o papel de D. João VI e dos jesuítas para dar início à sua produção nacional ao longo do século XIX; as cruzadas de Saint-Hilaire pelo Brasil daquele século e o reconhecimento da sua qualidade nacional; a solução dada por Louis Pasteur para a produção industrial do leite e do queijo em largas escalas; a criação do Regulamento de Inspeção Industrial e Sanitária de Produtos de Origem Animal (RIISPOA) por Getúlio Vargas em 1952; os detalhes por trás da "tolerância" às variedades de queijo "Minas" trazido em seu artigo 928; a influência do 
movimento sanitarista na regulação da produção de alimentos no Brasil; a truculência da ditadura militar durante a formação do Parque Nacional da Serra da Canastra na década de 1970; e, mais recentemente, os percalços enfrentados pelos produtores agroartesanais de queijo em todo Brasil para ver reconhecido o seu modo de produzir e comercializar alimento.

O imbróglio, de forma bastante objetiva, pode ser resumido da seguinte forma: desde 1952, com a edição do RIISPOA, para se produzir e comercializar queijo no Brasil é preciso adotar práticas industriais de produção incompatíveis com a tradição artesanal. Até o início do século 2000, o leite e o queijo só poderiam ser legalmente comercializados se passassem por processos industriais descritos no RIISPOA que envolvessem necessariamente sua pasteurização. As demais práticas, de acordo com o artigo 928 do RIISPOA, seriam toleradas. Ou seja, fazer queijo sem métodos tipicamente industriais ou fazer queijo utilizando leite cru eram formas que, na década de 1950, seriam toleradas - e não reguladas, protegidas ou fomentadas pelo Estado.

Aquilo que se revelava da história do queijo podia ser sentido nas interações com os produtores artesanais e seus produtos. A palestra do Presidente da APROCAN, João Carlos Leite, trouxe contornos muito além dos esperados, mostrando que as relações jurídicas entre a produção e consumo daquele alimento encetavam questões mais profundas em torno de disputas econômicas e políticas, pelos sentidos do desenvolvimento econômico, pelas formas de proteção à nossa cultura e pelo modo como o direito se relacionava com a intertemporalidade da história brasileira concernente ao tema - relações que pareciam remotas ou até mesmo desconectadas inicialmente. Isso se via também no debate ardiloso e emocionado que o tema revelava, colocando reguladores contra produtores, Estado contra consumidores. Enfim, visões de Estado e da forma como este se relaciona com o ambiente produtivo, merecendo, dessa forma, uma análise mais aprofundada e criteriosa.

Além disso, a narrativa indicava para mim que os desafios daquela comunidade de produtores agroartesanais permitiam extrapolar para questões jurídicas mais amplas, conectadas de forma prática, diária e real com a forma como o direito se relaciona com a proteção ou destruição de determinados modos de vida e suas culturas. Essas histórias de vida, o convívio com os produtores e as questões jurídicas que surgiam 
a partir da análise daquela realidade conduziram-me a essa guinada na pesquisa acadêmica para dedicar-me ao estudo da política agrícola brasileira, especificamente quanto à legislação e problemas jurídico-econômicos decorrentes da regulação histórica da produção agroartesanal do queijo de leite cru.

Com a decisão tomada e os rumos da pesquisa alterados, envolvi-me mais diretamente com os produtores agroartesanais da Canastra, pois passei a advogar probono para a APROCAN e conviver com seus problemas associativos, legislativos e na relação com os órgãos públicos. Tive a oportunidade também de acompanhar parte da premiação dos queijos brasileiros em 2017 durante o Mondial du Fromage de Tours na França durante a temporada de pesquisa que realizei em Paris.

Logo, é importante destacar desde já que meu papel como pesquisador do tema e militante na defesa da produção agroartesanal do queijo de leite cru muitas vezes se confunde.

Mais recentemente, o assunto ganhou ainda mais destaque após a notícia da apreensão e destruição de cerca de 160 quilos de produtos agroartesanais de origem animal durante o Rock in Rio de 2017, que fez os olhos da mídia se voltarem para o debate da proibição da circulação de produtos artesanais em nosso território. ${ }^{1}$ Em função do ocorrido, em novembro do mesmo ano, participei da organização de um abaixoassinado em defesa da produção agroartesanal no Brasil, que alcançou 25 mil assinaturas em pouco mais de 10 dias. $^{2}$

Nesse contexto, pesquisar um assunto em voga nos meios de comunicação trouxe um novo desafio à pesquisa, pois foi necessário refinar, da profusão de informações, aquilo que merecia ser analisado e que estaria, de certa forma, conectado ao meu objeto. Além disso, a notoriedade trouxe consigo uma aceleração da agenda política junto aos poderes legislativo e executivo federais, bem como nos principais Estados brasileiros, trazendo incertezas momentâneas em torno da validade metodológica do recorte inicialmente proposto. Permeia o trabalho a dúvida e a inquietude de querer

\footnotetext{
${ }^{1}$ As apreensões de queijos são recorrentes no Brasil, mas ganhou destaque após ter ocorrido com uma grande chef de cozinha, Roberta Sudbrack, que tem um extenso trabalho de apoio a pequenos produtores artesanais. O assunto foi tema do Bial, capa do Paladar, objeto de debates em todo o país.

${ }^{2}$ Disponível em: < https://www.change.org/p/presidente-da-rep\%C3\%BAblica-produtos-agroartesanaissem-fronteiras $>$. Acesso em 10 fev de 2018.
} 
extrapolar o campo de análise para todos os projetos, iniciativas e debates em torno da produção agroartesanal: mel, charcutaria, queijo artesanal de leite pasteurizado, processos de maturação de carnes, regulação sanitária de restaurantes e uma outra infinidade de temas. 


\section{INTRODUÇÃ̃o}

O debate sobre "queijo artesanal" ganhou destaque nacional nos últimos anos por uma situação sui generis vivida pela produção e comercialização de produtos agroartesanais de origem animal no Brasil. Atualmente, a legislação nacional regula esse mercado privilegiando a adoção de métodos industriais e controles sanitários para realidades produtivas cuja escala, métodos, preços e mercados destoam completamente daqueles utilizados pela agroindústria tradicional, ${ }^{3}$ como é o caso da produção agroartesanal brasileira.

O método de produção de queijo é muito semelhante em todo o mundo (FOX, 2008), pois implica essencialmente em um processo de desidratação da massa láctea na qual a gordura e a caseína do leite se concentram, algo entre seis e doze vezes, dependendo da variedade do queijo. A maior parte dos queijos do mundo é processada por meio da coagulação enzimática (coalhada) que emprega enzimas coagulantes. Assim, independente da região do globo onde aquela produção se concentra, o que cria a extensa variedade de queijos de leite cru que conhecemos, pode ser vinculado ao terroir: o capim que alimenta a vaca, a água da região, as enzimas o clima do local, os fungos que compõe o ambiente, o processo de maturação ${ }^{4}$ etc.

\footnotetext{
${ }^{3}$ Utilizaremos nesta tese o conceito de Geraldo Müller (1989a, p. 45-6) para definir o complexo agroindustrial: "Em termos formais, o complexo agroindustrial, CAI, pode ser definido como um conjunto formado pela sucessão de atividades vinculadas à produção e transformação de produtos agropecuários e florestais. Atividades, tais como: a geração destes produtos, seu beneficiamento/transformação e a produção de bens de capital e de insumos industriais para as atividades agrícolas; ainda: a coleta, a armazenagem, o transporte, a distribuição dos produtos industriais e agrícolas; e ademais: o financiamento, a pesquisa e a tecnologia, e a assistência técnica. As atividades são interdependentes, mas assimétricas, pois há aquelas cujas funções possuem um maior grau de importância na reprodução do complexo. Tais atividades constituem o núcleo do CAI e dizem respeito à capacidade de controle que os interesses socioeconômicos aí localizados exercem sobre a reprodução do mesmo. Assim, a agricultura, em que pese ser uma atividade principal, pode estar subordinada a setores industriais ou, até mesmo, a setores comerciais, como por exemplo, os supermercados. Do ponto de vista do conhecimento da estrutura e da dinâmica do complexo agroindustrial, o emprego dessa definição formal implica que se examinem as estruturas produtivas da agricultura, da indústria voltada para a agricultura e da indústria consumidora de matérias-primas agrícolas. Além disso, implica o estudo dos tipos de mercado dos vários setores que compõe o CAI e os mecanismos que provocam a expansão e o bloqueio do conjunto de atividades. Em síntese, o CAI é uma unidade de análise do processo socioeconômico que envolve a geração de produtos agrícolas, o beneficiamento e sua transformação, os serviços financeiros, técnicos e comerciais correspondentes, e os grupos sociais." Para uma revisão histórica do conceito, cf. BELIK, 2007.

${ }^{4}$ O termo maturação por vezes é substituído pela palavra “cura". Em entrevista realizada, João Carlos Leite não concorda com o uso do termo "cura" para designar o estágio de maturação do queijo (queijo meia cura
} 
Como destacam Villegas de Gante e Cervantes Escoto (2011, p. 150), o processo de produção do queijo artesanal extrapola em muito a simples coalhada do leite, visto que representa um bem cultural alimentício, suportando uma rede ou cadeia agroalimentar local de importância econômica, que pode contribuir para o desenvolvimento regional. Os autores lembram que a elaboração de um queijo artesanal também pode incorporar outros elementos vinculados a diferentes recursos que se encontram no território onde se produz o queijo, tais como (i) o saber tradicional, patrimonial, que se transmite dentro de uma determinada comunidade; (ii) a reputação vinculada a uma região reconhecida como produtora de um queijo particular, com determinada qualidade (sensorial e/ou identitária), que torna instransferível o saber fazer, territorializando a produção; (iii) a qualidade de leite e da microflora láctea vinculadas aos recursos naturais e à especialização pecuária.; (iv) a cultura de produção e o uso do queijo; (v) saberes relacionais que permitem o bom funcionamento de toda a cadeia produtiva. Trabalhadas em conjunto, essas práticas originam uma série de outros bens imateriais com características patrimoniais: paisagens, cultura, organização social, relação com a terra, organização da propriedade rural, fluxos monetários etc.

De um assunto que circulava em algumas rodas de conversa e meios especializados - como mistura de indignação e curiosidade com a situação ${ }^{5}$-, a questão eminentemente jurídica começou a ganhar grandes proporções, até se tornar de fato um problema da agenda legislativa e política do Estado brasileiro, tanto no nível federal quanto nos Estados e Municípios. Destacam-se três fatores recentes, expostos em seguida, que contribuíram para que o tema ganhasse relevância nacional, todos eles decorrentes da movimentação política dos setores relacionados à produção e à comercialização do queijo artesanal no Brasil, em especial no Estado de Minas Gerais.

Em 2008, após pressão dos produtores de queijo artesanal, o Instituto do Patrimônio Histórico e Artístico Nacional - IPHAN reconheceu o "Modo Artesanal de Fazer Queijo de Minas nas regiões do Serro, da Serra da Canastra e do Salitre" como patrimônio cultural e imaterial brasileiro. ${ }^{6}$ Este reconhecimento veio na esteira da pressão

ou curado), pois cura daria a entender que inicialmente o produto estaria estragado e precisaria deste período para não causar danos, o que, no entendimento do entrevistado, está equivocado.

${ }^{5}$ Conferir, neste sentido, Ratton (2011).

${ }^{6}$ Disponível em: 〈http://portal.iphan.gov.br/mg/pagina/detalhes/65>. Acesso em: 10 dez. 2018. 
política dos produtores de queijo artesanal do Estado de Minas pela legalização de sua produção, que sofria, à época, constantes apreensões por parte da Vigilância Sanitária. ${ }^{7}$

Anos mais tarde, em 2015, o queijo artesanal Capim Canastra, produzido por Guilherme Ferreira em São Roque de Minas/MG, ganhou a medalha de prata no Mondial du Fromage et des Produits Laitiers de Tours, na França - a primeira medalha internacional de um queijo brasileiro ${ }^{8}$; dois anos mais tarde e na esteira da primeira conquista, 11 queijos brasileiros foram premiados no mesmo concurso (com 12 medalhas), das regiões do Serro, Araxá, Serra do Salitre e Canastra, o que ampliou o reconhecimento em meios especializados internacionalmente a respeito da qualidade do queijo artesanal brasileiro.

Ainda em 2017, houve a apreensão de produtos artesanais de gênero alimentício da cozinha da chef Roberta Sudbrack durante a realização do Festival Rock in Rio, no Rio de Janeiro, levando ao descarte de mais de 80 quilos de queijo e 80 quilos de linguiça que não continham registro válido junto ao Serviço de Inspeção Federal - SIF ou o selo do Sistema Brasileiro de Inspeção de Produtos de Origem Animal - SISBI-POA. ${ }^{9}$

Durante todo esse período, ganhou destaque no debate nacional, inclusive na mídia de massa, a seguinte pergunta: afinal, quais são os problemas sanitários e legais que

\footnotetext{
${ }^{7}$ Neste sentido: "Fiscalização apreende quase $97 \mathrm{~kg}$ de queijo com rótulo adulterado em Santos Dumont, MG | Zona da Mata | G1. Disponível em https://glo.bo/2KevmOV, acesso em 05/01/2018; "Operação apreende cerca de 7,5 toneladas de queijo em Ouro Fino, MG | Sul de Minas | G1. Disponível em https://glo.bo/2wsoDic, acesso em 21/06/2017; "200 quilos de queijos sem nota e certificação de qualidade são apreendidos em Cruzeiro; carga de São Lourenço | Mix Vale. Disponível em http://bit.ly/2IrZdGv, acesso em 06/04/2017; "PMDF apreende uma tonelada de queijo sem nota fiscal. Disponível em http://bit.ly/2KeUllp, acesso em 22/06/2016; "PM de MG apreende 8 toneladas de queijo impróprio para consumo que ia para SP" - Notícias, Cotidiano. Disponível em http://bit.ly/2KfkzUv ,17/11/2015; "ENTERRADOS VIVOS: 13 mil queijos de leite cru da Serra da Canastra - Sertãobras. Disponível em http://bit.ly/2IuDo9b, acesso em 20/08/2017; "Mais de 6 mil quilos de queijo apreendidos em Minas Gerais - Sertãobras. Disponível em http://bit.ly/2KcQNzM, acesso em 10.01.2018.

${ }^{8}$ O queijo premiado foi do produtor Guilherme Ferreira, da Estância Capim Canastra, de São Roque de Minas/MG, filiado à APROCAN. O convite para participar do concurso internacional foi feito por Débora Pereira, da SerTãoBras, que se encarregou da compra do queijo no Mercado Central de Belo Horizonte por meio de um comerciante e afinador de queijos, João Belo, que o levou dentro da mala para a França. À época, o queijo não possuía registro no SISBI-POA, apenas no IMA: "Na mala. Ilegal, meu queijo não tinha nem rótulo. Não tinha nem SISBI essa época. Tinha o IMA, mas não tinha o rótulo, igual eu te falei. Aí cara, bombou. Do dia pra noite. Ela [Débora] me falou por Whatsapp, num grupo. 'Ah, então pessoal, um queijo brasileiro ganhou, acho que é do Guilherme. Mas só vou ficar sabendo 6 horas da tarde'. Isso era 6 horas da manhã. Ah, nem almocei. Passei o dia inteiro louco, passando mal. Aí, cara... Saiu! Não é por nada, mas eu acho que deu um up na Canastra, um up no queijo artesanal brasileiro." (2018).
}

9 Disponível em: <http://cultura.estadao.com.br/noticias/geral,estande-de-roberta-sudbrack-e-retirado-dorock-in-rio-apos-apreensao-de-alimentos,70002002627>. Acesso em: 04 abr. 2018. 
levam à proibição da produção e comercialização dos produtos artesanais? Esta pergunta se desdobra em outras, dentre as quais: como classificar um produto como artesanal? Ou então: como garantir que os controles de sanidade dos produtos não impeçam que produtos que preservem a cultura regional ou determinada produção artesanal cheguem ao consumidor?

O debate acerca da regulação da produção de queijo artesanal no Brasil se estende às questões jurídicas que permeiam também outras cadeias de produtos de origem animal - como a charcutaria e a produção do mel, por exemplo. Contudo, por conta da importância que o queijo tem na formação de parte de nossa cultura e da culinária regional, temos nele a possibilidade de enfrentar questões de uma forma mais ampla do que seria possível com outros gêneros alimentícios de origem animal. Nesse caminho, sustentaremos a expressão dessa cultura e de sua sociabilidade a partir da formação econômica do Brasil e seus ciclos de produção agrícola, tendo em vista que, apesar de nunca terem sido objeto de regulação específica por sempre ficarem à margem do que se entende como produção de alimentos, a cultura do queijo artesanal se moldou às limitações e constrangimentos impostos pela mesma regulação nacional que a desprezou enquanto elemento da produção - seja como expressão econômica ou mesmo o caráter de "ilegal" que recai sobre parte da reflexão acadêmica sobre o tema ${ }^{10}$ - preocupada desde o início do século XX com a questão do abastecimento do país.

Entendemos que, na forma como abordamos a produção do queijo artesanal de leite cru no curso desta tese, duas questões compõem nosso pano de fundo: a primeira, relaciona-se ao fato de que o queijo artesanal, enquanto expressão da organização de sua produção, não é um alimento essencial para o consumo das famílias, mas sim uma expressão cultural essencial à determinada forma de sociabilidade; em segundo lugar, a discussão em torno de sua regulação e sua produção artesanal é uma expressão bastante real da forma como o direito regula determinadas expressões culturais e, como tal, forma ou destrói mercados. Afinal, por que não podemos produzir, comercializar e comer queijo artesanal de leite cru em todo o país? Por que se nega acesso ao mercado "legalizado" a produtores de parte de nossa cultura alimentar, como os queijos mineiros artesanais? Por

${ }^{10}$ Cf.,CINTRÃO, Rosângela (2016). Sua tese debate a segurança, a qualidade e os riscos na regulação sanitária e a forma como essa legislação interpreta a produção de alimentos e os processos de (i)legalização dos queijos artesanais de leite cru em Minas Gerais. 
que não podemos fazer de nossa produção agroartesanal um elemento que valorize e dinamize a vida no campo, fixe as famílias naquela região e potencialize, assim, outras formas de exploração da terra e do trabalho no Brasil?

A peculiaridade dessas duas questões torna a problemática da regulação da produção e comércio do queijo distantes de uma discussão genuína em torno da segurança alimentar ou do direito de acesso ao alimento - conforme previsão dos direitos sociais inscritos no artigo $6^{\circ}$ da Constituição Federal. Entendemos, diferentemente, que sua regulação jurídica deveria estar mais atenta às previsões de proteção e fomento à cultura nacional, tal qual previsto no artigo 23, III, IV e V, artigo 24, VII e IV, artigo 30, IX e, em especial, aos artigos 215 e 216 . Nesse sentido, entendemos que tratar o alimento pela perspectiva tradicional de segurança alimentar, orientada como direito social, é anacrônica e merece ser reformulada adequadamente. Essas ponderações são necessárias tendo em vista que nosso trabalho não se situa como uma reflexão estrita sobre as questões de segurança alimentar de acesso ao alimento (food democracy), mas estejam vinculadas enquanto resistência alimentar daqueles que não produzem queijos nos mesmos moldes do que se faz na agroindústria. Ou seja, não há uma questão de combate à fome ou mesmo de regras de mercado para produção alimentar em massa, mas sim discutir quais seriam os critérios de proteção (food safety) que tal produção merece ter para viabilizar sua existência enquanto expressão cultural e histórica, que organizam determinada sociabilidade.

Tais questionamentos, adequadamente historicizados, serão de fundamental importância para analisarmos os desdobramentos da legislação que regula a produção de queijo no Brasil, em especial quando observamos certa clivagem entre o modelo industrial - que se baseia na pasteurização e no controle dos custos de produção para disponibilizar alimento barato e com alta capacidade de circulação em todo território nacional - daquele modelo artesanal/tradicional - voltado para cadeias de curto alcance, ${ }^{11}$ relacionado a métodos culturalmente preservados de produção de alimento.

\footnotetext{
${ }^{11}$ É interessante observar que nas entrevistas realizadas com os Deputados Federais Alceu Moreira (RS), Zé Silva (MG) e Evair de Melo (ES), a referência à necessidade de se estabelecer uma legislação sanitária que protegesse de alguma forma as cadeias produtivas de curto alcance foi assunto constante das intervenções, visto que, na visão dos deputados, a forma como a vigilância sanitária e a defesa agropecuária se estruturam
} 
Na região da Serra da Canastra, as distorções jurídicas do modelo brasileiro de regulação do produto agroartesanal ganham contornos impressionantes. Se, de um lado, o "Modo Artesanal de Fazer Queijo de Minas nas regiões do Serro, da Serra da Canastra e do Salitre" é reconhecido pelo IPHAN como patrimônio cultural e imaterial brasileiro desde 2008, por outro, a falta de reconhecimento sanitário da forma de se fazer o queijo artesanal, principalmente ao longo das três últimas décadas, foi tamanha que fez o número de produtores conhecidos minguar de cerca de 2000 no início da década de 1990 para 793 atualmente, conforme mapeamento realizado (SEBRAE; SICOOB; APROCAN, 2014). Desse modo, uma das razões para esse fato está intrinsicamente relacionado ao direito é: por ser tido como "ilegal" e ser "tolerado" desde a década de 1950, o produto é majoritariamente comercializado a preços muito baixos, inviabilizando o sustento das famílias de produtores rurais, que acabam por abandonar sua produção para se ocupar de outras atividades no campo, ou mesmo migrando para as cidades.

$\mathrm{Na}$ busca por respostas às perguntas colocadas anteriormente, esta tese tem como objetivo somar a análise legislativa e a documental ao tema, entrevistas com atoreschave envolvidos na regulação da produção agroartesanal no Brasil e análise bibliográfica de economia política, direito econômico e da regulação sanitária nacional e estrangeira. Assim, a discussão proposta insere-se nos estudos da política agrícola brasileira e está intrinsicamente conectada a temas bastante caros ao direito econômico, tais como a relação entre norma jurídica e soberania alimentar; debates em torno do desenvolvimento regional e dos sentidos do desenvolvimento econômico; as formas jurídicas que interferem no processo de formação e distribuição de renda; a leitura dogmática em torno das funções de abastecimento e controle sanitário, entre outros.

Pretendemos, com isso, compreender a estrutura e a função dos instrumentos jurídicos que organizam a produção agrícola brasileira, em momentos históricos específicos, bem como utilizar o ferramental do direito econômico "como instrumento de influência, manipulação e transformação da economia, vinculado a objetivos sociais ou coletivos, incorporando, desse modo, os conflitos entre a política e a economia" (BERCOVICI, 2009, p. 518). Com efeito, pretendemos, ao final, estruturar modelo jurídico que possa ser utilizado para tratar a heterogeneidade do sistema produtivo 
brasileiro a partir das contribuições que caibam ao direito, e que possa ser posteriormente estendido para outros setores de nossa produção agrícola. Logo, partimos do pressuposto da capacidade do Estado brasileiro de utilizar das técnicas de planejamento e intervenção no domínio econômico (GRAU, 1981a) para promover os objetivos garantidos pela Constituição Federal, em especial o combate às desigualdades regionais, a agregação e distribuição de renda, a efetivação de nossa política agrícola e a proteção e valorização de nosso patrimônio cultural.

Desde a perspectiva do Direito Econômico, raros foram os trabalhos que analisaram criticamente a política agrícola brasileira, seja em sua atual dimensão ou quanto à sua perspectiva histórica. ${ }^{12}$ A partir dos objetivos e hipóteses elencados, esta tese procura contribuir para a supressão de tal lacuna. Entendemos que a análise aqui proposta permitirá transpor para esse campo da atuação do Estado uma reflexão que alie não apenas a dimensão histórica e o mapeamento do quadro regulatório atual, mas também a problematização dos instrumentos à disposição do Estado para participar, absorver, induzir ou dirigir o desenvolvimento do setor - e fazê-lo a partir dos sentidos pretendidos de forma legítima e democrática por seus agentes políticos e econômicos. Em outras palavras, o trabalho contribui de forma inovadora com o direito econômico por pretender analisar a evolução legislativa da regulação dos produtos de origem animal, funcionalizando seus instrumentos aos sentidos de nossa política econômica no período analisado, isto é, buscamos articular a evolução legislativa a partir da primeira edição do RIISPOA ao projeto nacional-desenvolvimentista da década de 1950. Além disso, remontado o quadro histórico-institucional, analisaremos criticamente a estrutura regulatória instalada pelo Regulamento à luz dos princípios que passaram a orientar nossa

\footnotetext{
12 Esta constatação é fruto da somatória de três frentes. A primeira foi a busca na Biblioteca Digital de Teses e Dissertações (BDTD) do Instituto Brasileiro de Informação em Ciência e Tecnologia (IBICT) e na Biblioteca Digital da FAPESP, utilizando a palavras-chave "direito econômico" associada em pares com "política agrícola", "produção agrícola", "regulação sanitária". A segunda frente foi a busca no catálogo geral da Biblioteca da Faculdade de Direito da Universidade de São Paulo (USP), utilizando as combinações "política agrícola", "produção artesanal", "regulação sanitária", "queijo artesanal" e a palavrachave "direito econômico". Por fim, levamos em consideração as pesquisas realizadas e o conhecimento acumulado graças à nossa banca de exame de qualificação. Foram encontrados apenas as teses de Flávia Venturini, de 2006, intitulada "Denominação de origem: elemento fundamental às atuais empresas rurais", de Diogo Sant'Ana, de 2012, intitulada "Estado, direito e produção de alimentos: análise a partir do ponto de estrangulamento no setor de fertilizantes" e artigo de Fabiana de Menezes Soares e Letícia Camilo dos Santos intitulado "Diagnóstico e Análise do Sistema Normativo de Defesa Agropecuária Brasileiro", publicado na Revista da Faculdade de Direito da Universidade Federal de Minas Gerais, Belo Horizonte, n. 57, p. 321-434, jul./dez. 2010
} 
ordem econômica e pacto federativo adotado com a Constituição de 1988, atualizando os desafios colocados sobre a produção agroartesanal do queijo de leite cru. Logo, esse percurso nos permitirá vislumbrar, ao final, a criação de novos parâmetros para a construção do ordenamento jurídico para a regulação dessa produção, situando-a como eixo fundamental de nossa política agrícola e como item de grande relevância de nosso patrimônio cultural.

Com vistas a contribuir com o debate sobre os sentidos da intervenção do Estado na economia da produção e da cultura do queijo artesanal do Brasil, periférico e subdesenvolvido, o estudo de caso permitiu alcançar dois objetivos centrais. O primeiro é marcado pela proposição de um panorama do ordenamento jurídico que estrutura a produção e a cultura do queijo artesanal no Brasil desde o final do Império até a atual regulação federal sobre a questão. Assim, esse primeiro objetivo se faz necessário tendo em vista a escassa produção jurídica sobre a questão do queijo artesanal no Brasil, bem como a ausência de uma sistematização detalhada e menos emocionada do conjunto de normas que integram sua regulação - em especial após a série de eventos que jogou a questão em um embate pouco produtivo para a equalização da questão. O segundo objetivo é, a partir do método próprio ao direito econômico, sistematizar o imbróglio existente em torno da produção artesanal de queijo no Brasil, buscando apontar para uma regulação que consiga explicitar na sua forma jurídica uma economia política interessada na preservação de critérios seguros de produção do ponto de vista sanitário e de saúde pública, ao mesmo tempo que permitam a promoção de um bem imaterial de nossa cultura, como é o caso do Queijo Minas Artesanal.

Portanto, entenderemos as relações estabelecidas entre as formas manejadas pela regulação (e proibição) da produção do queijo artesanal no Brasil e a estrutura que essa regulação conforma, principalmente quanto aos seus aspectos econômicos e culturais. Elaborado o panorama histórico e identificados seus principais problemas, buscamos ao final analisar as principais propostas legislativas em curso para a regularização dos pequenos produtores de queijo artesanal de todo o Brasil.

Este caminho será realizado partindo da breve análise sobre a produção do queijo artesanal no mundo e o desenvolvimento de sua cultura, visando elucidar sua relação com o modo de produção mundial de alimentos desde a descoberta da pasteurização e a revolução provocada na indústria alimentícia, proposta pelos Estados 
Unidos a partir da Segunda Guerra Mundial. Procuraremos, nesse ponto, identificar o momento histórico em que a produção artesanal começou a concorrer com a produção industrial - com claros impactos em sua regulação.

Como justificativa, não encontramos registros que dão conta de unir essas duas frentes de análise, com foco na história da regulação do queijo artesanal no Brasil. Nesse caminho, é fundamental que a pesquisa possa promover tal estruturação histórica, o que permitirá uma visão mais ampla das questões jurídicas e políticas que envolvem a regulação da atividade no país. Organizado esse panorama, será possível proceder a conexão entre o Direito posto e as atuais dificuldades para a exploração dessa atividade econômica de forma condizente com sua importância para a cultura e economia brasileiras.

Assim, o objeto deste trabalho é analisar o processo de regulamentação de produtos agroartesanais no Brasil nos séculos XX e XXI, tendo como foco central a produção do queijo de leite cru na Serra da Canastra, mais especificamente em São Roque de Minas/MG. Em respeito às necessidades impostas pelo rigor científico, justifica-se o recorte metodológico pelas seguintes razões. Em primeiro lugar, porque a região da Canastra é uma referência nacional na produção de queijo artesanal de leite cru. Além disso, os trabalhos da Cooperativa de Crédito de São Roque de Minas (SAROMCREDI) e da Associação dos Produtores de Queijo da Canastra (APROCAN) são referência para outras regiões produtoras de queijo artesanal - seja em Minas Gerais ou em outros Estados brasileiros -, servindo como vanguarda para diversas iniciativas de organização de mercado e sua regulação em torno da produção queijeira. Ainda, vale destacar que esse foi o locus de onde partiram os primeiros movimentos pela legalização da produção do queijo artesanal de leite cru, influenciando o debate na Assembleia Legislativa de Minas Gerais e no Ministério da Agricultura para revisão da legislação aplicável ao tema há mais de quinze anos. Soma-se a isso o fato de que a APROCAN reunia, até a conclusão desta pesquisa, número expressivo de pequenos produtores organizados, bem como uma diretoria atuante e articulada com os órgãos públicos responsáveis pela gestão política e administrativa do tema, tais como o Ministério da Agricultura, Pecuária e Abastecimento (MAPA), Serviço Brasileiro de Apoio às Micro e Pequenas Empresas (SEBRAE), Instituto Mineiro de Agropecuária (IMA), Empresa de Pesquisa Agropecuária de Minas 
Gerais (EPAMIG) e outras associações de produtores e cooperativas de produtores rurais dedicadas ao queijo artesanal. ${ }^{13}$

A escolha desse recorte, porém, é consciente dos desafios e limites que ele acarreta. Justamente por seu protagonismo, a Serra da Canastra (e, especialmente, São Roque de Minas) também é motivo de grande discórdia entre aqueles que se dedicam à questão. Isso pode ser sintetizado nas frases ouvidas em debates sobre o tema: a Canastra não é o Brasil, querendo fazer crer - com razão - que aquela realidade não pode, nem deve, ser extrapolada acriticamente para outras (micro)regiões produtoras. É preciso cuidado ao tomar essa realidade como paradigma, em especial por estarmos lidando com um tema sensível ao Direito, que é a possibilidade de se regular um conceito abstrato como o "artesanal" em um país de dimensões culturais e territoriais tão grandes como o Brasil.

Por mais particular que possa parecer - uma cidade circunscrita pela Serra da Canastra, com menos de 10.000 habitantes e pouco mais de 300 produtores de queijo artesanal de leite cru -, a opção pelo estudo de caso permite uma aproximação diferenciada com o objeto de pesquisa, sem encerrá-lo ou limitar o produto final do trabalho a ele. Como método complementar de análise, permite buscar caminhos para conectar o tema com as discussões mais amplas proporcionadas pelas questões abordadas, além de permitir um diálogo mais direto e crítico com o campo teórico. Ou seja, a partir do caso concreto da produção agroartesanal de queijo de leite cru de São Roque de Minas, permite-se abstrair questões mais amplas da análise do direito econômico sobre a regulação da produção agroartesanal brasileira.

Por mais particular que possa parecer - uma cidade circunscrita pela Serra da Canastra, com menos de 10.000 habitantes e pouco mais de 300 produtores de queijo artesanal de leite cru -, a opção pelo estudo de caso permite uma aproximação diferenciada com o objeto de pesquisa, sem encerrá-lo ou limitar o produto final do trabalho a ele. Como método complementar de análise, permite-se buscar caminhos para conectar o tema com as discussões mais amplas proporcionadas pelas questões abordadas,

13 São 62 filiados de um total de 793 produtores cadastrados pelo IMA. Até a finalização desta pesquisa, não encontramos registro de outra associação de produtores de queijo artesanal dessa magnitude, tanto em nível de organização e frentes de trabalho, como em relação à quantidade de associados por total de produtores conhecidos. 
além de permitir um diálogo mais direto e crítico com o campo teórico. Ou seja, a partir do caso concreto da produção agroartesanal de queijo de leite cru de São Roque de Minas, é possível abstrair questões mais amplas da análise do direito econômico sobre a regulação da produção agroartesanal brasileira.

De forma concreta, desenvolvemos a pesquisa empírica por meio de observações participantes, resultantes do envolvimento que passamos a ter com a região e seus produtores. Acompanhamos diversas assembleias mensais da APROCAN, bem como reuniões na FAEMG e debates ao lado dos produtores, em fóruns que se estabeleceram a partir de 2016 para discutir os entraves da legislação e questões sanitárias relacionadas ao tema. Esse envolvimento permitiu também a abertura do diálogo com outras regiões produtoras, como a Serra do Salitre e o Serro, além da recém fundada Associação Paulista de Queijos Artesanais (APQA) e da Associação ComerQueijo, que reúne comerciantes especializados em produtos artesanais de origem animal de todo o país.

Desse modo, partindo da reflexão de Favret-Saada (2005) a respeito dos impactos da experiência da pessoa pesquisadora e do descompasso do tempo da análise teórica com o tempo da vivência, a realização das observações participantes assimilou os ensinamentos de Schritzmeyer (2007, p. 119) de que a experiência etnográfica não pode ser uma busca por encaixar-se em modelos teóricos, mas sim de permitir vivências e percepções que compõem uma dentre várias narrativas possíveis.

Foi por meio da pesquisa de campo, que entramos em contato prático e direto com a realidade da Associação, combinada ao estudo da legislação, que se revelou a intrincada cadeia de problemas jurídicos relacionados à produção agroartesanal brasileira de alimentos de origem animal sobre a qual discorreremos ao longo desta tese.

Com relação à pesquisa documental e bibliográfica, realizamos um mapeamento rigoroso da legislação brasileira a partir de 1920, visto que, de nosso ponto de vista, as análises que se proliferam encontram-se fragmentadas ou enviesadas a um ou outro lado da disputa, sem possuir elementos históricos e políticos que possam auxiliar à resolução da questão. Ademais, pelo crescimento do movimento político em torno do objeto da pesquisa, recorremos também a entrevistas com atores-chave que se dedicam à 
questão, tanto no poder público como nos movimentos políticos e associativos vinculados à legalização da produção agroartesanal de queijo.

Aplicado a esse substrato, o método do direito econômico foi propício para extrair as questões que necessitavam análise aprofundada e criteriosa, com vistas a identificar as relações de poder e os sentidos de cada disputa identificada. Por fim, o estudo de caso nos serviu como elemento aglutinador entre teoria e pesquisa empírica, permitindo uma comunicação e inter-relacionamento ao longo de todo trabalho para avaliar os desdobramentos e contornos das questões analisadas.

Destarte, foi necessário comparar e recorrer à experiência francesa de regulação da produção de queijo artesanal - que enfrentaram questões semelhantes ao caso brasileiro ao longo das décadas de 1980, 1990 e 2000. Para isso, realizamos uma breve temporada de pesquisa na França, na cidade de Paris, que nos permitiu mapear a forma como aquele país atravessou desafios semelhantes em torno da regulação da produção queijeira especialmente quando da constituição da zona do Euro, nos últimos 30 anos, tornando possível extrair semelhanças e identificar as diferenças dos modelos de regulação de cada país, essencial para evitarmos a replicação de modelos de forma acrítica e descontextualizada. Em suma, o objeto desta tese será analisado mediante (i) pesquisa de campo, (ii) pesquisa documental e bibliográfica; (iii) o método do direito econômico; e (iv) referências pontuais ao direito comparado.

Da análise crítica do objeto de pesquisa e do estudo de caso, escolhemos organizar nossa reflexão em torno de três capítulos: (i) a análise da economia política presente na história da regulação da produção agroartesanal no Brasil nos séculos XIX e XX e sua relação com o projeto nacional desenvolvimentista de Getúlio Vargas, circunstanciado aqui na forma como se regulou, em 1952, a produção alimentar de origem animal (RIISPOA); (ii) entender, a partir do RIISPOA, a forma como o Estado brasileiro se organizou para regular a produção alimentar de origem animal e identificar os principais entraves jurídicos à regulação da produção de queijo artesanal de leite cru no Brasil; e, por fim, (iii) avaliar, pelo estudo de caso da Canastra, como o direito econômico pode servir como instrumento para enfrentar as contradições do processo de desenvolvimento local e como serviria para harmonizar as diferentes formas (industrial e artesanal) de se produzir queijos no país. A partir da realidade atual dessa cadeia produtiva e de suas normas jurídicas, o primeiro capítulo pretende explorar as raízes e 
problemas oriundos acerca da economia política praticada ao longo dos séculos XIX e XX que merecem ser exploradas para uma correta colocação das questões atuais. Para a análise dessas questões, recorremos ao mapeamento da bibliografia especializada, que permeia uma análise histórica, sociológica, econômica e legislativa do período. Mais especificamente, os capítulos se estruturarão da seguinte forma:

Num primeiro momento, buscaremos identificar os elementos de economia política que conformam essa realidade no Brasil, trazendo na história dos séculos XIX e $\mathrm{XX}$ os contornos e transtornos de se regular a produção de alimentos de origem animal tal qual se fez no RIISPOA, visando entender quais foram os desafios que uma economia agrário-exportadora e escravocrata, de grandes latifúndios, encetou para o projeto nacional-desenvolvimentista de Vargas entre as décadas de 1930 e 1950 . A partir deste marco, procuraremos compreender a forma como a regulação do queijo se relaciona com isso e quais os desafios são colocados para a formação econômica do Brasil que se conformava até então.

No segundo capítulo, remontaremos a legislação brasileira que regula os produtos de origem animal desde o início da década de 1920. Essa organização da legislação brasileira foi necessária tendo em vista dois propósitos específicos: lidar diretamente com os temas decorrentes de nossa forma federativa de organização do Estado, bem como buscar organizar, sistematizar e dar alguma linearidade à normas que lidam com a regulação industrial e sanitária de produtos de origem animal no país. Esse ponto merece especial atenção, pois notamos a necessidade de uma delimitação conceitualmente adequada dos sujeitos e objetos da regulação agroartesanal de origem animal brasileira - demasiadamente fragmentada e fonte de grande parte dos problemas experimentados na atualidade. Nesse mesmo capítulo, descreveremos a forma como o Estado brasileiro se organizou para regular e fomentar a indústria brasileira de laticínios desde 1950, preocupado com o abastecimento da população que migrava para as cidades fruto do processo de industrialização - em um dos maiores movimentos de êxodo rural conhecidos no mundo. A partir deste marco, será possível identificar os sentidos do desenvolvimento da indústria de laticínios, aliado à uma leitura sobre a dogmática das funções de abastecimento e de controle sanitário pretendidos pelo Estado desde 1950 até os dias de hoje. 
Esta reconstrução, desse modo, nos permitirá enfrentar algumas dificuldades do direito econômico, justamente relacionada à dificuldade de se integrar (regular) o produto e a produção artesanal dentro do sistema produtivo tal qual o conhecemos e, consequentemente, lidar com as dificuldades decorrentes disso - como a pressão da grande indústria pela apropriação daqueles valores subjetivos; a forma de controle sanitário sobre um método de produção diferenciado; a pressão sobre a urbanização das cidades produtoras; a preservação da cultura enquanto patrimônio imaterial etc.

Em relação ao terceiro capítulo, analisaremos especificamente como as discussões e conclusões dos capítulos anteriores se projetam na pesquisa empírica proposta. Por meio de entrevistas com produtores rurais, membros do poder público e atores que se relacionam com o queijo da Canastra, buscaremos identificar as formas de melhor intermediar os conflitos entre o direito e a produção agroartesanal do queijo de leite cru.

Com esse panorama, será possível compreender de forma mais objetiva o papel do direito e problematizar sua vinculação estrita à eficiência do processo de acumulação, sendo necessário buscar bens de outra grandeza que estejam articulados à acumulação e mereçam dessa área um tratamento protetivo (de bens culturais, do desenvolvimento regional e do meio ambiente, entre outros). Ou seja, a partir da constatação de que existem duas realidades distintas típicas de nossa dualidade estrutural $^{14}$ na forma de se produzir alimentos de origem animal, o passo seguinte é buscarmos os ajustes ou concessões a serem feitas pelo direito para a convivência mais harmoniosa desses dois sistemas, sem perder de vista a necessidade de lidar com as consequências da regulação da produção agroartesanal inserida na circulação capitalista sem desconfigurar seus elementos diferenciadores.

Assim, os elementos sociais, culturais e econômicos identificados na produção do queijo artesanal de leite cru serão fundamentais à identificação das formas jurídicas do direito econômico que potencialmente podem proteger ou promover uma

\footnotetext{
${ }^{14}$ Novamente recorremos à análise de Müller (1989a, p. 48): "Há, sem sombra a dúvidas, uma desigualdade na difusão do progresso técnico na agricultura brasileira tomada em seu conjunto, assim como desigualdade nas formas de organização da produção, no acesso a financiamento, na organização institucional dos interesses sociais associados às atividades agrícolas. Mas pensamos que se pode subscrever tais qualificações apenas na medida em que elas permitem identificar o que há de novo na 'dualidade estrutural', na 'modernização localizada', na 'heterogeneidade estrutural' e que este novo dá a direção dos processos em curso no agro nacional"
} 
harmonização na aparente guerra instalada no mercado lácteo brasileiro, de modo a permitir a convivência dessas duas formas de se produzir e comercializar o queijo no Brasil, ao propor uma regulação que consiga diminuir o grau conflitivo e emocionado sobre qual tema é atualmente debatido no Brasil. 


\section{CONCLUSÃO}

Ao longo desta pesquisa, vimos que as características da produção agrícola brasileira foram modificadas na medida em que a América Latina passou a adotar políticas econômicas orientadas à intensificação do processo de industrialização capitalista e, com isso, almejavam alterar o sentido de seu desenvolvimento socioeconômico. Este período e os processos políticos, sociais e econômicos nele incutidos foram objeto de amplos e dedicados estudos, aqui parcialmente mapeados. Assim, o que nos interessa marcar, fundamentalmente, é a mudança de orientação do processo econômico e, a partir dele, a problemática adaptação instrumental que passou a ser feita na legislação dedicada à regulação da produção de alimentos de origem animal, carentes de uma reorganização política típica de um planejamento agrícola, que enfrente adequadamente as múltiplas tensões existentes no campo, dando-lhes respostas institucionais e legais adequadas. A produção agroartesanal, neste sentido, parece-nos apresentar elementos importantes para a alteração do processo de acumulação por meio da estratégia que Sunkel denominou "desarrollo desde dentro".

Se não for possível criar condições de se agregar valor à produção do queijo artesanal de leite cru nos padrões aqui propostos, entendemos que restarão inviabilizadas formas valorosas de se fixar dignamente as pessoas na terra, além de se abrir mão da proteção de nosso mercado interno e, portanto, de nosso patrimônio. Agregar valor - e mantê-lo -, numa produção com as características do queijo artesanal, pode recompor a médio-longo prazo a pressão feita pela expansão de culturas agrícolas pensadas exclusivamente na perspectiva dos lucros. Por conseguinte, os fins do controle sanitário devem estar articulados à política agrícola e aos princípios de nossa ordem econômica.

Apesar de termos modernizado a forma de organização de nossa produção agrícola, continuamos, de certa maneira, presos aos mesmos quadros da economia colonial na produção de queijos de leite cru, justamente porque a forma de utilização da terra continua a se fazer "não em função da população que nela trabalha e exerce suas atividades, e sim essencialmente e em primeiro lugar, em função de interesses comerciais e necessidades inteiramente estranhas àquela população” (PRADO JUNIOR, 1979, p. 50), conforme vimos pela inadequação da legislação sanitária ao aparato agroartesanal. 
Continuamos, também, presos aos quadros coloniais com relação ao exercício da atividade de se produzir queijo artesanal de leite cru, visto que ainda não incorporamos decente e maciçamente os 30.000 produtores agroartesanais atualmente mapeados no Brasil.

A regularização da produção agroartesanal de queijo de leite cru, como dos demais itens vinculados à cadeia de produtos de origem animal, possibilitaria o fortalecimento de cadeias secundárias em função do aumento do mercado consumidor a que teriam acesso. Ademais, a adoção de determinadas práticas de produção e sua regularização dá acesso a mercados consumidores que remuneram o produto três a quatro vezes mais do que o mercado estabelecido para o queijo irregular, materializado na figura do queijeiro tradicional. Dar acesso ao mercado nacional e internacional a um produto com as características do queijo de leite cru brasileiro proporcionaria um incremento de renda significativo àquela população rural, o que pode fortalecer tais cadeias produtivas a ponto de tirá-las da sombra da agricultura primária.

A cada passo que demos neste trabalho, restou evidente que o esforço para se equacionar a questão da regulação da produção artesanal de queijo de leite cru demanda o desenvolvimento de mais pesquisas, tanto no Direito quanto em outras ciências, a fim de aclarar questões relativas à sua cadeia produtiva, às relações com a grande indústria de laticínios, às delimitações adequadas dos riscos sanitários e formas modernas para seu controle, às questões relativas ao crédito e assistência técnica, ao aprofundamento da discussão em torno da autorregulação ou certificação do setor, à função do associativismo e cooperativismo, aos impactos no desenvolvimento regional, enfim, para resolver questões que os juristas, sanitaristas, historiadores e sociólogos ainda não se ocuparam detidamente. Em nosso percurso, esperamos ao menos ter aberto oportunidade para estes novos questionamentos.

Buscamos, nesse ínterim, ser objetivos nas medidas que nos parecem ser mais adequadas para viabilizar e harmonizar um determinado tipo de produção social e cultural de alimento às regras de controle sanitário, que continuam válidas e extremamente importantes para a vida em sociedade e garantia do direito à saúde. Nesse sentido, esforçamo-nos para demonstrar que processos de produção artesanal de alimento possuem valores que merecem proteção efetiva pelo Direito. Exemplo disso é o que vem sendo 
feito com a utilização da indicação de procedência e a denominação de origem controlada em diversas regiões do globo, incluindo a Serra da Canastra.

Ao nosso ver, aplicar métodos distintos de controle sanitário aos dois modelos de produção de queijos é tautológico. É possível alcançar a mesma finalidade por formas diferentes de controle e contribuir, assim, com o desenvolvimento brasileiro. Esse passo ainda precisa ser dado, mas aparentamos estar no caminho certo, ao menos em termos de ampliação do escopo dos debates em torno da temática. Se esta conclusão encerra o processo de redação desta tese, não encerrará a mobilização no sentido de preservar e valorizar a cultura do queijo artesanal de leite cru no país. 


\section{REFERÊNCIAS BIBLIOGRÁFICAS}

ABRAMOVAY, R. Subsídios e multifuncionalidade na política agrícola europeia. Revista de Economia e Sociologia Rural, v. 40, p. 235-264, 2002.

ABRAMOVAY, R.; VEIGA, J. E. da. Novas instituições para o desenvolvimento rural: o caso do Programa Nacional de Fortalecimento da Agricultrua Familiar (PRONAF). São Paulo: IPE/USP, 1998.

ABREU, A. A. de. Ponto IVDicionário Histórico-Biográfico Brasileiro. Rio de Janeiro: CPDOC, [s.d.]. Disponível em: <http://www.fgv.br/cpdoc/acervo/arquivo>. Acesso em: 12 maio. 2018.

AGÊNCIA ESTADO. Órgão diz que apreensão de alimentos no Rock in Rio foi conforme lei. 16 set. 2017. Disponível em: $<$ http://www.correiobraziliense.com.br/app/noticia/diversao-earte/2017/09/16/interna_diversao_arte,626591/orgao-diz-apreensao-de-alimentos-norock-in-rio-foi-conforme-lei.shtml>.

AGRIFERT. Resumo Propostas de princípios de delimitação para pedido de Indicação Geográfica do Queijo Artesanal da Serra da Canastra. [s.l: s.n.].

AGRIFERT. Demonstração da notoriedade histórica e cultural da Canastra para o queijo minas artesanalEMATER-MG, , jul. 2009. .

AITH, F. Curso de Direito Sanitário - a proteção do direito à saúde no Brasil. São Paulo: Quartier Latin, 2007.

ALEM, N. de M. O Direito Econômico da Cultura: uma análise dos gastos públicos indiretos com cultura. 2017. Universidade de São Paulo - Faculdade de Direito, São Paulo, 2017.

ALMEIDA, E. F.; FERNANDES, M. R. Caracterização da Microrregião da Canastra como Produtora do Queijo Minas Artesanal. São Roque de Minas/Minas Gerais: EMATER-MG, 2004.

ALMEIDA, P. H. de M. A Indicação de Procedência do Queijo Minas Artesanal Canastra. Painel apresentado em I Seminário Nacional de Indicações Geográficas. Caxias do Sul, 25 set. 2013. . Disponível em: <https://www.ucs.br/site/eventos/1oseminario-nacional-sobre-indicacoes-geograficas/programa/>. Acesso em: 10 fev. 2018. 
ANDRADE, C. R. de. Diagnóstico da qualidade microbiológica de queijo Serra da Canastra e caracterização de bactérias do gênero enterocococcus. 2009. Universidade Estadual de Campinas, Campinas/SP, 2009.

ARRIGHI, G. O Longo Século XX: dinheiro, poder e as origens de nosso tempo. Traducao Vera Ribeiro. Rio de Janeiro: Contraponto, 1996.

BANDEIRA DE MELlO, C. A. Curso de Direito Administrativo. 30a ed. São Paulo: Malheiros, 2013.

BATTISTOTTI, B.; BOTTAZI, V.; PICCINARDI, A.; VOLPATO, G. (ed.). Quesos del Mundo. Traducao Lionello Tetri; Nuria Espinós. Barcelona: Elfos, 1985.

BELIK, W. Agroindústria e Política Agroindustrial no Brasil. In: Dimensões do Agronegócio Brasileiro: Políticas, Instituições e Perspectivas. Brasília/DF: MDA, 2007.

BELIK, W. Desenvolvimento Territorial e Soberania Alimentar. In: ALMEIDA FILHO, N.; RAMOS, P. (Ed.). Segurança Alimentar, Produção Agrícola e Desenvolvimento Territorial. $1^{a}$ ed. Campinas/SP: Alínea, 2010. p. 169-192.

BERCOVICI, G. Desigualdades regionais, Estado e Constituição. São Paulo: Max Limonad, 2003.

BERCOVICI, G. O ainda indispensável Direito Econômico. In: BENEVIDES, M. V.; BERCOVICI, G.; MELO, C. (Ed.). Direito Humanos. Democracia e República homenagem a Fábio Konder Comparato. São Paulo: Quartier Latin, 2009.

BERCOVICI, G. A Atuação do Estado Brasileiro no Domínio Econômico. IPEA Livro 9, v. 3, p. 473-498, 2010.

BERCOVICI, G. Direito econômico do petróleo e dos recursos minerais. São Paulo: Quartier Latin, 2011a.

BERCOVICI, G. Direito econômico do petróleo e dos recursos minerais. São Paulo: Quartier Latin, 2011b.

BERCOVICI, G. A ordem econômica constitucional e a política agrícola. Revista Fórum de Direito Financeiro e Econômico - RFDFE, v. ano 6, n. n. 10, p. 27-36, fev. 2017.

BIELSCHOWSKY, R. Pensamento econômico brasileiro: o ciclo ideológico do desenvolvimentismo. $3^{\text {a }}$ ed. Rio de Janeiro: Contraponto, 1996.

BOBBIO, N. Da estrutura à função: novos estudos de teoria do direito. Traducao Daniela Beccaria VERSIANI. Barueri/SP: Manole, 2007. 
BORELli, B. M. Caracterização dos Indicadores Higiênico-Sanitários e da Diversidade de Leveduras Durante a Fabricação do Queijo Minas Curado Produzido na Serra da Canastra. 2002. Universidade Federal de Minas Gerais, Belo Horizonte/MG, 2002.

BOSI, A. A Arqueologia do Estado-Providência: Sobre um Enxerto de Idéias de Longa Duração. In: Dialética da Colonização. São Paulo: Companhia das Letras, 1993. p. 273307.

BRAGA, M. A. C. Subdesenvolvimento, Tecnologia e Direito Econômico: o programa nacional de nanotecnologia e o desafio furtadiano. 2013. Universidade de São Paulo - Faculdade de Direito, São Paulo, 2013.

BRAUDEL, F. Civilização Material, Economia e Capitalismo - século XV-XVIII - as estruturas do cotidiano: o possível e o impossível. $1^{\text {a }}$ ed. São Paulo: Martins Fontes, 2005. v. Volume 1

BRAUDEL, F. Civilização Material, Economia e Capitalismo: séculos XV-XVIII - o

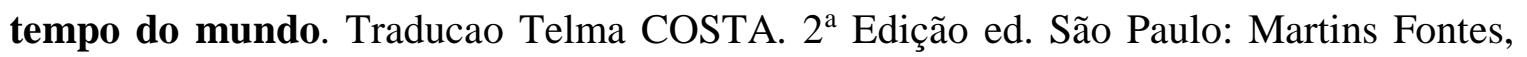
2009. v. Volume 3

BUAINAIN, A. M. Modelo e Principais Instrumentos de Regulação Setorial: Uma Nova Didática. In: Dimensões do Agronegócio Brasileiro: Políticas, Instituições e Perspectivas. Brasília/DF: MDA, 2007. p. 53-102.

CALICCHIO, V. Missão AbbinkDicionário Histórico-Biográfico Brasileiro. Rio de Janeiro: CPDOC, [s.d.]. Disponível em: <http://www.fgv.br/cpdoc/acervo/dicionarios/verbete-tematico/missao-abbink>.

CAPISTRANO DE ABREU, J. Capítulos de história colonial: 1500-1800 \& os caminhos antigos e o povoamento do Brasil. $2^{\mathrm{a}}$ ed. Brasília: Editora Universidade de Brasília, 1998.

CARVALHO, A.; LEITE, J. A cidade morria devagar - o romance de uma cooperativa. $2^{\mathrm{a}}$ ed. Belo Horizonte/MG: Armazém das ideias, 2014.

CINTRÃO, R. P. Segurança, qualidade e riscos: a regulação sanitária e os processos de (i)legalização dos queijos artesanais de leite cru em Minas Gerais. 2016a. Universidade Federal Rural do Rio de Janeiro, Rio de Janeiro/RJ, 2016. Disponível em: <http://www.sertaobras.org.br/wp-content/uploads/2017/03/TESE-BIBI-CINTRAOVersao-Final-2016.pdf>. Acesso em: 17 jun. 2017. 
CINTRÃO, R. P. Segurança, qualidade e riscos: a regulação sanitária e os processos de (i)legalização dos queijos artesanais de leite cru em Minas Gerais. 2016b. Universidade Federal Rural do Rio de Janeiro, Rio de Janeiro/RJ, 2016.

COLIN, A. Géohistoire des fromages français. Annales de Géographie, v. 118, n. 667, p. $349,2009$.

COMPARATO, F. K. O indispensável direito econômico. In: Ensaios e pareceres de direito empresarial. Rio de Janeiro: Forense, 1978. p. 453-72.

CRAVO, M. A.; COTRIM, W. S. Análise comparativa da legislação brasileira e europeia para queijos artesanais. Cadernos de Pós-Graduação da FAZU, v. 2, 2011. Disponível em: <http://www.fazu.br/ojs/index.php/posfazu/article/viewFile/413/305>. Acesso em: 12 maio. 2018.

CRUZ, F. T. da. Qualidade dos Alimentos e escalas de produção: em defesa de critérios e normas para legitimação dos produtos artesanais/tradicionais. In: $47^{\circ}$ CONGRESSO DA SOCIEDADE BRASILEIRA DE ECONOMIA, ADMINISTRAÇÃO E SOCIOLOGIA RURAL. Porto Alegre/RS, 26 jul. 2009. . Disponível em: <http://www.sober.org.br/palestra/13/846.pdf>. Acesso em: $10 \mathrm{dez} .2017$.

CRUZ, F. T. da. Produtores, consumidores e valorização de produtos tradicionais: um estudo sobre qualidade de alimentos a partir do caso do Queijo Serrano dos Campos de Cima da Serra - RS. 2012. Universidade Federal do Rio Grande do Sul, Porto Alegre/RS, 2012.

CRUZ, F. T.; SCHNEIDER, S. Qualidade dos alimentos, escalas de produção e valorização de produtos tradicionais. Revista Brasileira de Agroecologia, v. 5, n. 2, p. 22-38, 2010.

DE CHIARA, J. T. Disciplina jurídica das instituições financeiras. Revista de Direito Público, v. 41/42, p. 289-307, 1977.

DE CHIARA, J. T. Operações de crédito contratada com o Estado: análise das relações. Cadernos de Direito Econômico, v. 1, p. 229, 1983.

DELFOSSE, C. La diffusion mondiali de la consommation de fromage, de l'ingrédient de pizza au produit de terroir. Pour la revue du grep, p. 123-129, mar. 2012.

DENIS, F. Brasil. [s.1.] Editora da Universidade de São Paulo, 1980.

DIAS, J. C. Uma longa e deliciosa viagem - O primeiro livro da história do queijo no Brasil. São Paulo: Barleus, 2010. 
DINIZ, M. F. S. Queijo Canastra: um estudo envolvendo aspectos culturais e parâmetros de inocuidade do alimento. 2013. Universidade de São Paulo - Escola Superior de Agricultura “Luiz de Queiroz”, Piracicaba, 2013.

DIXON, P. H. European systems for the safe production of raw milk cheese. Vermont Cheese Council, 2000.

DOLABELLA, R. H. C. Regulamento da Inspeção Industrial e Sanitária de Produtos de Origem Animal (RIISPOA)Consultoria Legislativa da Câmara dos Deputados, , 2012. . Disponível em: <http://bd.camara.gov.br/bd/bitstream/handle/bdcamara/9911/regulamento_inspecao_dola bella.pdf?sequence=2>. Acesso em: 4 jan. 2018.

DORES, M. T. das; FERREIRA, C. L. de L. F. Quejo Minas Artesanal, Tradição centenária: ameaças e desafios. Revista Brasileira de Agropecuária Sustentável, v. 2, n. 2, p. 26-34, 2012.

DÓRIA, C. A. Queijo minas não há mais? Trópico, 5 abr. 2008. Disponível em: <http://www.sertaobras.org.br/artigos-de-carlos-dria/queijo-minas-mais/>. Acesso em: 12 jan. 2018.

DÓRIA, C. A. Formação da Culinária Brasileira. São Paulo: Três Estrelas, 2014.

DORIGON, C. Mercados de Produtos Coloniais da Região Oeste de Santa Catarina: em Construção. 2008. Universidade Federal do Rio de Janeiro, Rio de Janeiro, 2008. Disponível em: <http://objdig.ufrj.br/60/teses/coppe_d/ClovisDorigon.pdf>.

DUPIN, L.; PAXSON, H. Resenhas - The life of cheese - crafting food and value in America. Mana, v. 21, n. 3, p. 672-675, dez. 2015.

EMATER. Programa Queijo Minas Artesanal: mapa do queijo. Disponível em: <http://www.emater.mg.gov.br/portal.cgi?flagweb=site_tpl_queijo\&id=3299>. Acesso em: 10 dez. 2017.

FAVRET-SAADA, J. Ser afetado. Cadernos de Campo, v. 13, p. 155-161, 2005.

FECAROTTA, L. Apreensão de alimentos no Rock in Rio mostra anacronismo de lei. 18 set. 2016. Disponível em: <http://www1.folha.uol.com.br/ilustrada/2017/09/1919428legislacao-datada-e-burocratica-mina-cozinha-brasileira.shtml >.

FEDERICI, S. Revolution at Point Zero: Housework, Reproduction, and Feminist Struggle. Oakland: PM Press, 2012. 
FERRAZ, P. Apreensões de produtos artesanais no Rio reacendem polêmica sobre legislação. 20 set. 2016.

FERREIRA, C. L. de L. F.; FERREIRA, É. G. Implicações da madeira na identidade e segurança dos queijos artesanais. Rev. Inst. Latic. "Cândido Tostes", v. 381, n. 66, p. 13-20, ago. 2011.

FERTILE, G. F. Programa de apoio aos queijos tradicionais de fabricação artesanal de Minas Gerais - Resumo e Metas - Resultados em fevereiro/2003. p. 11, 2003.

FLANDRIN, J.-L.; TEUTEBERG, H. J. The transformation of the European diet. In: Food - A Culinary History from Antiquity to the Present. New York: Columbia University Press, 1999. p. não paginado [ebook].

FONSECA, P. C. D. Nem ortodoxia nem populismo: o Segundo Governo Vargas e a economia brasileira. In: LIMA, M. C. (Ed.). Os boêmios cívicos: a assessoria econômico-política de Vargas (1951-54). Rio de Janeiro: E-papers : Centro Internacional Celso Furtado de Políticas para o Desenvolvimento, 2013. p. 17-65.

FONSECA, P. C. D. Vargas: o capitalismo em construção. São Paulo: Hucitec, 2014.

FOX, P. F. Cheese: Chemistry, Physics and Microbiology. $3^{\mathrm{a}}$ ed. Estados Unidos da América: Elsevier, 2008.

FRANCO, M. S. de C. Homens Livres na Ordem Escravocrata. 4. ed. São Paulo: Unesp, 2010.

FREYRE, G. Casa-Grande e Senzala. São Paulo: Global, 2003.

FURTADO, C. Desenvolvimento e subdesenvolvimento. São Paulo: Fundo de Cultura, 1961.

FURTADO, C. Brasil: a construção interrompida. $3^{\text {a }}$ ed. Rio de Janeiro: Paz e Terra, 1992.

FURTADO, C. Teoria e Política do desenvolvimento econômico. São Paulo: Paz e Terra, 2000.

FURTADO, C. Formação Econômica do Brasil. São Paulo: Companhia das Letras, 2006.

FURTADO, C. Criatividade e dependência na civilização industrial. São Paulo: Companhia das Letras, 2008. 
GRAU, E. R. Planejamento Econômico e Regra Jurídica. 4. ed. São Paulo: Revista dos Tribunais, 1978.

GRAU, E. R. Elementos de Direito Econômico. São Paulo: Revista dos Tribunais, 1981a.

GRAU, E. R. Elementos de Direito Econômico. [s.1.] Revista dos Tribunais, 1981b.

GRAU, E. R. A ordem econômica na Constituição de 1988. 13. ed. São Paulo: Malheiros, 2000.

Gulherme. Entrevista Gulherme, 19 mar. 2018. .

HARVEY, D. Condição Pós-Moderna. 17ª ed. São Paulo/SP: Loyola, 2008.

HUNT, E. K.; LAUTZENHEISER, M. History of Economic Thought: a critical perspective. 3rd. Edition ed. New York: M.E. Sharpe, 2011.

INSTITUTO DO PATRIMÔNIO HISTÓRICO E ARTÍSTICO NACIONAL - IPHAN. Modo artesanal de fazer queijo de Minas: Serro, Serra da Canastra e Serra do Salitre/Alto Paranaíba. [s.l: s.n.]

KINDSTEDT, P. Cheese and Culture: a history of cheese and its place in Western Civilization. Vermont/US: Chelsea Green Publishing, 2012.

KNOLL, L. P. Origins of the regulation of raw milk cheeses in the United States. abr. 2005. Disponível em: <https://dash.harvard.edu/handle/1/8852188>.

KOSIKOWSKI, F. V.; MOCQUOT, G. Progrés de la technologie du fromage. Études agricolas de la FAO, n. 38, p. 264, 1958.

LAURE, G. Propostas de princípios de delimitação para pedido de Indicação Geográfica de Queijo Artesanal da Serra da Canastra. [s.l: s.n.].

LIMA, M. C. A Assessoria Econômica do segundo governo Vargas e a cosntrução do Estado brasileiro moderno. In: Os boêmios cívicos: a assessoria econômico-política de Vargas (1951-54). $1^{\mathrm{a}}$ ed. Rio de Janeiro: Centro Internacional Celso Furtado de Políticas para o Desenvolvimento, 2013. p. 175-227.

LINHARES, M. Y. L.; SILVA, F. C. T. da. História Política do Abastecimento (19181974). Brasília: BINAGRI - Biblioteca Nacional de Agricultura, 1979.

LUCCHESE, G. Globalização e regulação sanitária - os rumos da vigilância sanitária no Brasil. 2001. Fundação Oswaldo Cruz, Rio de Janeiro, 2001. 
MARTIUS, K. F. P. V.; SPIX, J. B. V. Viagem pelo Brasil 1817 - 1820. [s.l.] Itatiaia, 1981. v. 4

MARX, K. O Capital: crítica da economia política. Traducao Reginaldo Sant'Anna. $22^{\text {a }}$ ed. Rio de Janeiro: Civilização Brasileira, 2008. v. Livro I, Volume 2

MATOS, L. A. I. O conhecimento regional do queijo minas artesanal na indicação de procedência Canastra: ensinando o padre a rezar. 2016. Universidade Federal do Rio de Janeiro, Rio de Janeiro/RJ, 2016.

MAWE, J. Viagens ao Interior do Brasil. Belo Horizonte: Itatiaia, 1978.

MELlO, J. M. C. de. O Capitalismo Tardio: contribuição à revisão crítica da formação e do desenvolvimento da economia brasileira. $8^{\text {a }}$ edição ed. São Paulo: Brasiliense, 1990.

MENEZES, S. de S. M. A força dos laços de proximidade na tradição e inovação no/do território sergipano das fabriquetas de queijo. 2009. Universidade Federal de Sergipe, São Cristovão/SE, 2009. Disponível em: <https://ri.ufs.br/bitstream/riufs/5474/1/SONIA_SOUZA_MENDONCA_MENEZES.pdf $>$.

MERGAREJO NETTO, M. A geografia do Queijo Minas Artesanal. Belo Horizonte/MG: Edição do Autor, 2014.

MONTANARI, M. Food is Culture. New York: Columbia University Press, 2006.

MÜlLER, G. Estado, Estrutura Agrária e População: Estagnação e Incoporação Regional. Petrópolis: Vozes, 1980.

MÜlleR, G. Complexo Agroindustrial e Modernização Agrária. São Paulo: HUCITEC: EDUC, 1989a.

MÜLLER, G. O rural e o industrial na transição agrária brasileira. In: D'INCAO, M. (Ed.). História ideal: ensaios sobre Caio Prado Jr. São Paulo: Brasiliense, 1989b.

NIEDERLE, P. A. Indicações geográficas: qualidade e origem nos mercados alimentares. Porto Alegre/RS: UFRGS, 2013.

NOVAIS, F. O Brasil nos quadros do antigo sistema colonial. In: MOTA, C. G. (Ed.). Brasil em perspectiva. Rio de Janeiro: Bertrand Brasil, 1990. p. 47-63.

OLIVEIRA, F. de. Crítica à razão dualista / O ornintorrinco. São Paulo: Boitempo, 2003. 
PAXSON, H. Post-pasteurian cultures: the microbiopolitics of raw-milk cheese in the United States. Cultural Anthropology, v. 23, p. 15-47, 2008.

PAXSON, H. The life of cheese - crafting food and value in America. [s.1.] Universty of California Press, 2013.

PEREIRA, J. M. M. A Política Agrária do Banco Mundial em Questão. Estudos Avançados 20, v. 57, p. 355-383, 2006.

PEREIRA, L. de P. Crédito rural e Cooperativismo. Curitiba: Juruá, 1993.

PODER360. Contra apreensão no Rock in Rio, deputados fazem degustação de queijos. 22 set. 2017. Disponível em: <https://www.poder360.com.br/governo/contra-apreensaono-rock-in-rio-deputados-fazem-degustacao-de-queijos/>.

PRADO JUNIOR, C. A Questão Agrária. São Paulo: Brasiliense, 1979.

PREBISCH, R. O desenvolvimento econômico da América Latina e alguns de seus principais problemas. In: O Manifesto Latino-Americano e outros ensaios. Traducao Vera RIBEIRO; Lisa STUART; Cesar BENJAMIN. Rio de Janeiro: Contraponto, 2011. p. 95-152.

RATTON, H. O Mineiro e o QueijoQuimera Fimes, , 2011. .

RODRIGUES, C. C. Brasiliana e Reconquista do Brasil: projetos editoriais de traduções. Revista Letras, v. 85, n. Editora UFPR, p. 219-230, jun. 2012.

ROSEnAU, M. J. The Milk Question. Boston: Houghton Mifflin Company, 1912.

SAINT-HILAIRE, A. Segunda Viagem do Rio de Janeiro a Minas Gerais e a São Paulo - 1822. Belo Horizonte: Itatiaia, 1974.

SAINT-HILAIRE, A. Viagem às Nascentes do Rio São Francisco. Belo Horizonte: Itatiaia, 1975.

SANTiago, F. A Influência do Preço e do Crédito de Custeio na Produção Agrícola Brasileira. 1986. Fundação Getúlio Vargas, Rio de Janeiro/RJ, 1986.

SCHILLING, P. Trigo: o trigo e o latifúndio no Rio Grande do Sul - o acordo do trgo norte-americano - perspectiva da triticultura gaúcha. Rio de Janeiro: Instituto Superior de Estudos Brasileiros, 1959.

SCHRITZMEYER, A. L. P. Etnografia dissonante dos tribunais do Júri. Tempo soc. [online], v. 19, p. 111-129, 2007. 
SEBRAE/MG; SICOOB - SAROMCREDI; APROCAN; RAMOS, P. D. A. M.; VALENTE, M. E. R. Cadastro georreferenciado dos produtores de queijo minas artesanal da região da Serra da Canastra. [s.l: s.n.].

SERRANO, G. de A. Memória e História na coleção Reconquista do Brasil: Minas no Brasil. Outros Tempos, v. 11, p. 280-294, 2014.

SHATZMANN, R. Manuel des fromageries ou introduction a l'industrie du lait. Traducao L. J Jomini; Th. Eckerfeld. $3^{\mathrm{a}}$ ed. [s.l: s.n.]

SIMONSEN, R. C. Evolução Industrial do Brasil e Outros Estudos. [s.1.] Companhia Nacional, 1973.

SIQUEIRA, R. Terra Deu, Terra ComeVideoFilmes, , 2010. .

SOARES, F. de M.; SANTOS, L. C. dos. Diagnóstico e Análise do Sistema Normativo de Defesa Agropecuária Brasileiro. Rev. Fac. Direito UFMG, v. n. 57, p. 321-434, dez. 2010.

SOUSA, G. S. de. Tratado Descritivo do Brasil em 1587. [s.l: s.n.]

STOKES, D. O quadrante de Pasteur: a ciência básica e a inovação tecnológica. Traducao José Emilio Maiorino. Campinas: Unicamp, 2005.

STURTZ, J. J. A review financial, statistical and commercial of the Empire of Brazil and its resources. London: Effingham Wilson, 1837.

SUNKEL, O. Del desarrollo Hacia Adentro al Desarrollo Desde Dentro. Revista Mexicana de Sociología, v. 53, n. 1, p. 3-42, 1991.

SYLVANDER, B.; BEINCOURT, O. Negotiating standards for animal products: a procedural approach applied to unpasteurized milk. In: Agricultural standards: the shape of the global food and fiber system. Dordrecht: Kluewr Academic Publishers, 2004.

TAVARES, M. da C. Da Substituição de Importações ao Capitalismo Financeiro. [s.1.] Zahar, 1974.

TRENTINI, F. Denominação de origem: elemento fundamental às atuais empresas rurais. 2006. Universidade de São Paulo, São Paulo, 2006.

TRINDADE, O. A. D. C. O Mercosul no direito brasileiro: incorporação de normas e segurança jurídica. Belo Horizonte: Del Rey, 2007. 
TSCHUDI, J. J. von. Viagem às províncias do Rio de Janeiro e S. Paulo. Traducao Eduardo de Lima CASTRO. São Paulo: Martins, 1953.

VARGAS, G. D. Plataforma de Aliança Liberal (1930). In: Diretrizes da nova política do Brasil. Rio de Janeiro: José Olympio, 1942.

VELlOSO, J. M. da C. O fazendeiro do Brazil: do leite, do queijo e da manteiga. Rio de Janeiro: Brasiliana, 1798.

VILLEGAS DE GANTE, A.; CERVANTES ESCOTO, F. La genuinidad y tipicidad en la revalozación de los quesos artesanales mexicanos. Estud. soc [online], v. 19, n. 38, p. 145-164, 2011.

VILlELla, A. V.; SUZIGAN, W. Política do Governo e Crescimento da Economia Brasileira, 1889-1945. Rio de Janeiro: IPEA/INPES, 1973. 